\title{
Strategies for Determining the Production Cost and Pricing of Garments in Ghana: A Study of the Fashion Industries
}

\author{
Peggy Maansah Ankai Howard \\ Faculty of Creative Arts and Technology \\ Kumasi Technical University-Kumasi. \\ Dr. Michael Ato Essuman \\ Dean of Students \\ Kumasi Technical University-Kumasi. \\ Faculty of Creative Arts and Technology \\ Kumasi Technical University-Kumasi. \\ Thomas Obeng Asare \\ Faculty of Creative Arts and Technology \\ Kumasi Technical University-Kumasi
}

\begin{abstract}
A good number of companies rely on the intuition and the market experience of their managers to price their products. Nonetheless, many business and marketing executives still face pricing difficulties. In the light of this, the study investigated the strategies employed in the Ghanaian fashion industries in costing and pricing their garments including the satisfaction level with their profit margin. With descriptive research and cross sectional survey through nonprobability sampling techniques, data was collected from 210 respondents comprising company owners and workers in the fashion industry from Accra, Kumasi and Sunyani. Using mixed method approach, the study found that most companies as part of their strategies determined the detailed and actual garment cost by mostly considering the profit, fabric, labor, trim cost and overheads. The quality of the garments, market competition, production cost, company characteristics, and age of the client including company location largely influenced garment pricing in Ghana. Cost plus method, market analysis, discount strategy, customer based pricing and market segmentation were the most popular approaches to fixing garment prices. For a successful pricing, fashion producers should be creative, listen to their clients, do their homework well, improve their records and be flexible. Though a higher proportion of the enterprises were satisfied with their profit margin, notwithstanding, the study recommends that fashion producers should be educated on the right principles of costing and pricing so as to ensure increased profit.
\end{abstract}

Keywords: Garments, production cost, pricing strategies, fashion industry, profit margin, and satisfaction

\subsection{Introduction and Rationale}

Fashion industry plays very important part in the socioeconomic development of every nation as it facilitates the generation of income for living and provides the means for people to acquire their clothing needs (Sarpong, Howard \& Osei-Ntiri, 2011). For example, the value of the global fashion industry amounts to 3 trillion dollars, forming 2 percent of the world's Gross Domestic Product (GDP). Between 1990 and 2014, the number of people employed in the Textiles and Clothing Industry increased from 34.2 million to 57.8 million respectively (Global Fashion Industry statistics). Fashion is a structurally diverse industry, covering major international retailers, wholesalers, large design houses as well as one-person design shops. The industry provides employment for people across occupations such as fashion designers, computer programmers, lawyers, accountants, copywriters, social media directors, and project managers. On the account of the California Fashion Association, manufacturing is only a fraction of the modern apparel industry as "it is a highly sophisticated industry involving fashion and market research, brand licensing/intellectual property rights, design, materials engineering, product manufacturing, marketing and finally, distribution" (California Fashion Association, 2011). The industry is expected to bring about a considerable degree of creativity and innovations aiming at meeting the aesthetic design and utility expectations of consumers. Fashion design may also be an epitome of art, culture and symbolism. Universally, fashion constitutes a multi-billion dollar industry and creates jobs for designers, models, beauticians and make-up artists, producers, textile designers, manufacturers, event organisers and many others. Naturally, it is also connected to other creative industries, including the arts, film and music (Nkube, 2018). 
A dynamic Fashion Industry is said to be emerging in Africa and this has been described as 'fashion's new frontier' (Jennings, 2011). Like the developed countries, Nigerian fashion has created female entrepreneurs and has improved the Nigerian economy by creating jobs and opportunities and creativity (Madichie, 2009).

Statistics on Ghana's Fashion Industry is limited but it is an undeniable fact that many people have been employed in the industry. The Ghanaian Garment Sector mainly comprises of small-scale dressmakers established as one person business (Ampofo, 2011) as found in (Amankwah, Badoe \& Chichi, 2014). The size of the company is defined by the type of equipment available and the number of apprentices it has. Most enterprises are small-scale, some are medium sized, and very few can be categorized as large. Companies in the garment industry in Ghana specialize in kaba (traditional dress) and kaftan, wedding dresses, shroud garments, office apparel, uniforms and suits. Majority of the enterprises make custom-made clothing (sew and fit) and a few produce ready-to-wear products ('sew and sell') (Ghana Skills Development Initiative, 2013-2017). Most of the fashion companies are 'street fashion shops' because they are not formally structured unlike the emerging fashion houses. The designers, (tailors) are found in kiosks, containers or rented stores often decorated with popular fashion calendars and have been the major determinant of the popular fashion trends in the country. While some develop most of their inspiration from their environment and everyday people, others are influenced by international fashion trends through internet and frequent news media. Many of the youth pick up their style ideas from fashion portals online and come out with distinctive outfits for dressmakers to sew. In the last few years, emerging fashion houses have to cope with street designers as people find the street fashion shops more affordable. Usually some of the ready-made garments are bought in bulk by expatriate clients to sell in Europe and North America. This sort of business is bringing in thousands of US dollars a month to a section of the fashion designers (Osei Kwadwo, 2014). The main Ghanaian fashion export destinations comprises EU countries, U.S.A. and some parts of the ECOWAS. However there has been a decline due to competition with other African countries including poor finishing of products culminating in products not meeting the required standards (Quartey, 2006). Also, the quantum of income accrued from fashion products is low as compared to countries like China, India and Hong Kong who are enjoying a considerable amount of money from their export earnings (Sarpong et al., 2011).

In an attempt to improve that, efforts have been made by successive governments to develop and improve the industrial sector of the country. Resultantly, fashion education has been made part of the curriculum at the tertiary institutions of Ghana's educational institutions. The products of such institutions are required to acquire quality demand-driven employable and marketable skills that can make them functional in the industrial sector (Amankwah, 2007) as found in (Sarpong et al., 2011). Sarpong et al, (2011) were of the view that to address the challenges posed by the importation of new and used clothing and textiles to the fashion industry, fashion producers must have knowledge in pricing and information as to how to penetrate through the fashion market successfully (Easey, 2002). Indeed some of the SMEs (small and medium-scale enterprises) face difficulty when determining the production cost and pricing of their items and this has left in its wake the challenges resulting in either under-pricing or over pricing of products by the smallscale fashion businesses. Within the last decade in Ghana, there has been evidence of literature publications on issues bordering on fashion, clothing and textiles (such as Dramedo, 2009; Sarpong et al., 2011; Ampofo, 2011; Amankwaa et al., 2012; Essel \& Ammissah, 2015) but nothing is found on the strategies determining the production cost and pricing of garments in the Ghanaian Fashion Industry. This current study sought to verify the strategies employed by the Ghanaian fashion providers in costing and pricing their garments. In so doing, the study determined:

- The various strategies used to cost garments in Ghana.

- The various strategies used to price garments in Ghana.

- The satisfaction level of companies with their profit margin.

\section{Hypothesis}

There is no difference in the satisfaction levels of the profit margin of the three categories of fashion companies in Ghana.

\section{Definition of Terms}

- Industry in this paper refers to business, company, enterprises and are therefore used interchangeably.

- Fashion producers refer to fashion providers, fashion companies, fashion designers.

\subsection{Literature Review}

\subsection{Strategies for Determining the Production Cost of Garments}

\subsubsection{Cost and Production Cost of Garments}

According to World Bank as presented by James Ruth, cost is the total money, time, and resources associated with a purchase or activity. 
Keiser et al., (2008) indicates that the monetary value used to produce a garment is referred to as cost and this embraces the material, labor as well as overhead expenses of the company. The cost of manufacturing is obtained at the sample development stage by considering the general manufacturing parameters such as raw material cost (fabric, trims, and accessories), manufacturing overheads (processing, finishing, and packing), administrative overheads, cost of sipping and the profit. In most cases, cost is influenced by the existing market prices of the raw materials and overheads which are based on experience. At the sample development stage, the approved product cost is then negotiated with a potential buyer for placement of orders (Gandhi \& Poonkuzhali, 2015). The major components in a garments cost are materials (fabrics), trims and labor. Trims, include support materials (interlining, lining and other support devices), closures, threads, elastics and labels. Fabric has often been found to be the biggest single cost. The type and quality of the fabric chosen makes a great difference in the overall cost of the garment. The quantity of fabric is also most difficult to estimate due to some waste encountered during the cutting process (Keiser et al., 2008). The cost of garment embraces components such as fabric, trims, cut, make and trim charges, value added services (such as printing, embroidery, washing, applique), testing of the garment quality, transportation and logistics cost and profit of the manufacturing organization (Kothari, 2013). Out of the three chief classes of cost for garment manufacturers, usually direct material costs take approximately between 45-60 percent of the total garment cost, and on the average close to half of the total cost. This means that designers can influence cost through their choice of fabrics, trims and design details and that any decision taking during designing definitely affects garment cost (Jeffrey \& Evans 2011, 8-9; Keiser \& Garner 2008, 465-466). Direct labor also caters for $20 \%$ of the total cost whereas overheads forms about $30 \%$ of the total cost (Jeffrey \& Evans, 2011, 8).

\subsubsection{Different Stages of Garment Costing}

Garment costing entails many elements relative to many other products. The number of steps adopted by a particular company is dependent on its size and the process structure. The four different stages of garment costing are preliminary costing, cost estimating, detailed costing, and actual costs (Myers-McDevitt 2011, 13-14). Preliminary costing is performed before making the samples whereas estimated construction costs are calculated based on old, similar styles that have been produced earlier. New fabric and possible modifications to the design are considered at this stage in order to ensure accurate estimate. This stage ensures time saving and resources for both the design staff and the production and merchandising teams (Myers-McDevitt 2011, 14-15). Cost estimating being the second stage, is based on actual samples that is the sample instruction sheet, garment components, fabric, trims, labor and manufacturing costs. This stage can suffer slight inaccuracies since it is based on the sample and sample lengths of the fabric. The next stage is about the detailed costing and is done just before production starts. Essentially, when actual production layouts are in place and accurate fabric consumption data is available, anything that might have been forgotten in the sample stage could be included here. Moreover, it is at this point that the actual sewing methods are made available. It sometimes involves changes to styles to make garment less expensive for mass production (Myers-McDevitt 2011, 1415). The actual costs being one of the most important costing processes can only be ascertained after production. The costs computation is made after all the data after production (actual cost of material, trims and labor) are known. In certain instances, the budgeted costs are exceeded due to unexpected circumstances. This only provides new information for future production and garment design (Keiser and Garner 2008, 467-471; Myers-McDevitt 2011, 1415). Choudhary (2015), opine that there are two stages involved when costing garments- that is pre-cost and final cost. Pre-cost refers to the preliminary estimate of the garment prior to its adoption into the line. In this case the designers must keep the fabric, trim and the labor cost per each garment within the limit the company sets for a particular line price range. The final cost involves the use of actual figures for materials and labor to do the exact computation and this is more often than not done by the costing or import department.

\subsection{Pricing Strategies}

According to Li (2014), price is the amount of money charged for a product or service. It is the most adaptable component of the marketing mix hampering directly and over a short period over the degree of profit and cost effectiveness of a company (Simon, Bilstein, \& Luby, 2008). Pricing has been considered as the easiest strategy within marketing, probably due to the fact that a lot of companies use intuition and the manager's market experience to determine their prices (Simon, 1992). But it has been the number one problem many business and marketing executives get faced with ( $\mathrm{Li}, 2014)$.

\subsubsection{Factors Influencing Pricing}

Several studies in the fast food restaurants have shown that odds and cents pricing (Carmin et al., 1990; Liang \& Kanetkar, 2006; Naipaul \& Parsa, 2001), quality of the product, costs, characteristics, location, and competition (Carmin et al., 1990), status (LaFontaine, 1995; Graddy, 1999; Ater et al., 2010; Kalnins, 2003) and demographics of the area (Graddy, 1997; Stewart \& Davis, 2005) have influence on pricing. 
Other studies have presented contradictory results on how the racial composition of an area affects pricing. For example, Jekanowski (1998) revealed that fast food prices were lower in areas with higher percentage of African Americans, whereas Graddy indicates that fast food prices were positively related to the proportion of African Americans.

\subsubsection{Approaches to Pricing}

According to Hinterhuber (2008), prices have a high impact on companies' profitability, and pricing strategies vary considerably between sectors and market situations. Nevertheless, researchers mostly agree that pricing strategies can be categorized in three big groups: cost-based pricing, competition-based pricing and customer value-based pricing (Nagle \& Holden, 2003; Phillips, 2005). Cost-plus pricing is the oldest and most popular approach which requires determining the cost of each product and adding a profit margin on costs. With this method, sellers are certain about costs, and buyers feel it is fair ( $\mathrm{Li}, 2014)$. This approach is generally preferred by financial departments, since its usage guarantees adequate margin per the sale of each product (Phillips 2005, 24). Market-based pricing usually refers to the practice of pricing based on the prices offered by the competition. It can also be an effective strategy for a low-cost supplier seeking to enter a new market. At most extreme, this approach allows the competition to set the prices (Phillips $2005,24)$. Value-based pricing in the broadest sense, refers to the self-evident idea that price should be related to customer value. In the narrowest sense it refers to one-to-one pricing in which customers are quoted different prices according to their value for the product being sold. It is not the most appropriate for selling goods it rather suits services better (Phillips 2005, 24-26). The three stated approaches are often blended in company's pricing strategies and no single approach is used always. Companies adjust and integrate various methods to achieve different goals (Phillips 2005, 26). Good-value pricing offers the right combination of quality and good service at a fair price (Li, 2014). Other pricing strategies such as high and low pricing, penetration pricing, yield management, price testing, price skimming, discount strategy competition-based pricing, market segmentation and estimation made by experts do exist. High and low pricing involves charging higher prices on daily basis but running frequent promotions to lower prices temporarily on selected items $(\mathrm{Li}, 2014)$. High price is accepted if it agrees with the value of the product perceived by the customers, otherwise such a strategy may lead to commercial failure. A low price strategy may also lead to a commercial success, especially in the food retailing sector for instance, low price retailers. The success of a low price strategy depends on the number of clients attracted by the product since the low margin should be compensated by a higher number of items sold (Dolgui \& Proth, 2017). Penetration pricing consists of setting an initial price lower than the existing market price in anticipation of breaking down customers' purchasing habits. Basically, it aims at obtaining a larger market share. Penetration pricing leads to cost reduction pressure and discourages the entry of competitors $(\mathrm{Li}$, 2014). Yield management is a procedure that seeks to make the maximum profits through the use of information about buying behaviour and sales to bring about pricing and inventory controls (Lee-Ross \& Johns, 1997). Over the years, there have been many literatures outlining the positive impacts of yield management on company level (Barth 2002; Cross 1997). For instance, it provides more benefits to customers thus leading to greater performance, increased efficiency and productivity and also competitive advantage (Esse, 2003). Boahen, Quansah \& Sarpong (2013) concluded in their study that the implementation of yield management has positive impact on their hotel business operations in the Kumasi Metropolis with respect to profitability, competitive advantage, operational efficiency, productivity and cost saving. Price skimming strategy has to do with an initial fixing of a high price, and then reducing it over time. It is almost like the price discrimination however this goes with the time factor. Customarily, price skimming is applicable to customers who are comparatively less price sensitive (such as clients of cosmetic industry). Likewise, price skimming applies when customers get fascinated by some innovations (specifically electronic items like computers) (Dolgui \& Proth, 2017). Price testing approach consists of changing the price of the item under consideration and taking note of the number of items that could be sold. This can be done playing with a scale shop or a shop simulated on computer with different classes of customers, according to their age, gender, the level of incomes and /or the buying habits, and so on. This enables price to be defined and moreover help select most profitable market niche (Dolgui \& Proth, 2010). Discount strategy concerns itself with selling a given set of items at a reduced price for a limited period. Bolton (1989), Blattberg \& Neslin, (1990) and also Bemmaor \& Mouchoux (1991) have provided some instances. This reduction ought to generate sufficient supplementary sales to make up for the reduction in income. Nonetheless, this is not always the case and a handful of companies get the actual discount cost. Competition-based pricing uses as key information the competitors' price levels, including behaviour expectations, observed in real competitors and/or potential primary sources to determine adequate pricing levels to be practiced by the company (Liozu \& Hinterhuber, 2012). Market segmentation (or price discrimination) strategy consists of segmenting the market and charging a different price for each segment, depending on the willingness of the customers to pay more or less to purchase the item (Dolgui \& Proth, 2017). 
Estimation made by experts' method is useful when new items are being introduced on the market. For example, when advancement in technology results in altering an existing item, or when the competition changes drastically. The first step of the method involves taking note of the views of several experts (number not less than ten) and not in contact with each other. Because they are distant from each other, different selling curves are realized. Working sessions are then organised with these experts so as to find common grounds for agreement of their estimations / recommendations (Dolgui \& Proth, 2017). Market analysis studies how attractive and dynamic a market within a special industry is by defining the market, segmenting it, identifying the target market, establishing the market trends, and so on (Radulescu, 2012). The pricing process at the manufacturer starts with sending all needed information about materials and trims to the manufacturer. All materials and trim components need to be counted and their total price calculated, in addition to possible transportation costs (Goworek 2007, 84-85; Jeffrey \& Evans 2011, 8-9).

\subsection{Methodology}

Enterprises/ industries in Ghana are classified into micro, small, medium and large scales and various criteria according to the nature of the enterprise/industry have been ascribed to that. This mode of classification has either been based on both fixed assets and the number of employees or only on the number of employees per the enterprise in question. For instance, the Venture Capital Fund Act 2004 (Act 608); Ghana Enterprise Development Commission (GEDC) (Act 1975; National Board for Small Scale Industries (NBSSI), (1990, 1998); Aryeetey et al. (1994); Osei et. al (1993); Kayanula \& Quartey, (2000) among others. In consideration of the nature of the fashion industries in Ghana, the study deemed it fit to adopt the NBSSI criteria which uses only the number of employees. The NBSSI describes enterprises with less than 5 employees as 'micro', 6 to 29 as 'small', 30 to 99 as 'medium' and more than 100 as large.

The study's primary data was collected from self-administered questionnaire administered by the researchers at the fashion homes / houses and companies in Accra, Kumasi and Sunyani metropolises. The study was conducted between September and November 2018, and data was gathered on variables relating to strategies for determining the cost of production and pricing of garments in the fashion industry. The study basically employed descriptive research (Isaac \& Michael, 1995) and applied cross sectional survey to collect data in order to make inferences about the population at that point in time (Lavrakas, 2008). The study used purposive sampling (Tashakkori \& Teddlie, 2003a) as well as snowball sampling techniques (Vogt, 1999) to select the respondents' companies. The questionnaires had a preamble spelling out the rationale for the study as well as a statement assuring respondents of the necessary confidentiality and anonymity deserved (Frankael \& Wallen, 2003). Though the instruments were taking through the test of validity and reliability, opportunity was offered for clarification and explanations to the respondents who needed help. Respondents used between 20 and 25 minutes to complete one questionnaire. The questionnaire data covered (1) Bio data /Personal records (e.g. gender, age, educational qualification, job schedule, experience in the fashion industry, company classification, customer category, location of the company and source of the fabrics), (2) Strategies for determining the production cost of garments, (3) Garment pricing and (4) Satisfaction level of the company. Questionnaire items were adapted from the literature. Appropriate Likert scale types were employed to gather the data. For example, 3 -point scale ranging from "not at all" to "great extent" was used to find out the stages the companies follow when costing their products whereas 5 -points scale was used to establish the factors companies consider to arrive at their production cost. In exploring the factors that influence a company's garment pricing, 5 -point scale covering "not all" to "very great extent" was applied. Again, respondents were given a number of approaches to pricing from which they were required to select those they normally employ when pricing their garments. Respondents were also asked to indicate the degree of importance they attach to given tips to follow to ensure successful pricing based on 5-point scale ranging from "unimportant" to "very important". Another 5-point Likert scale ranging from "very unsatisfied" to "very satisfied" was used to elicit data on the satisfaction level of the respondents concerning their profit margin. About $96 \%$ of the companies approached completed and returned their questionnaires. The study also occasionally employed unstructured interview to gather more information to complete the result. The survey data was analyzed using descriptive statistics (i.e. frequency, mean, standard deviation) and mean response analysis was used to rank the responses. Inferential statistics such as Kruskal -Wallis test helped to establish the statistical difference between the companies regarding their level of satisfaction (Hinton, 2004). The Cronbach alpha value of the questionnaire items was 0.867, an indication of excellent reliability (Hinton, 2004).

\subsection{Results and Discussion}

\subsection{Demographic Characteristics of the Respondents.}

In all, 210 (100\%) questionnaires were analyzed made up of 53.3\% male and 46.7\% female from Accra, Kumasi and Sunyani. 
Table 1: Demographic Characteristics of the Respondents

\begin{tabular}{|c|c|c|}
\hline Variables & Frequency & Percentage frequency \\
\hline \multicolumn{3}{|l|}{ Gender } \\
\hline Male & 112 & 53.3 \\
\hline Female & 98 & 46.7 \\
\hline Total & 210 & 100 \\
\hline \multicolumn{3}{|l|}{ Age Category in Years } \\
\hline$<20$ & 4 & 1.9 \\
\hline $21-30$ & 126 & 60 \\
\hline $31-40$ & 56 & 26.7 \\
\hline $41-50$ & 18 & 8.6 \\
\hline $51-60$ & 6 & 2.9 \\
\hline $60>$ & 0 & 0 \\
\hline Total & 210 & 100 \\
\hline \multicolumn{3}{|l|}{ Highest Educational Qualification } \\
\hline Elementary/Junior High School & 18 & 8.6 \\
\hline Intermediate & 14 & 6.7 \\
\hline Senior High School & 6 & 2.9 \\
\hline Advance & 10 & 4.8 \\
\hline Higher National Diploma & 138 & 65.7 \\
\hline Bachelor / Bachelor of Technology & 20 & 9.5 \\
\hline Masters & 2 & 1.0 \\
\hline Doctorate & 2 & 1.0 \\
\hline Total & 210 & 100 \\
\hline \multicolumn{3}{|l|}{ Experience in the Garment Industry } \\
\hline$<1$ & 22 & 10.5 \\
\hline $1-5$ & 116 & 55.2 \\
\hline $6-10$ & 36 & 17.1 \\
\hline $11-15$ & 20 & 9.5 \\
\hline $16-20$ & 6 & 2.9 \\
\hline $21-25$ & 4 & 1.9 \\
\hline $26-30$ & 2 & 1.0 \\
\hline $30>$ & 4 & 1.9 \\
\hline Total & 210 & 100 \\
\hline \multicolumn{3}{|l|}{ Nature of Respondents' Company } \\
\hline Local & 204 & 97.1 \\
\hline Foreign & 6 & 2.9 \\
\hline Total & 210 & 100 \\
\hline \multicolumn{3}{|c|}{ Classification of Respondents' Company } \\
\hline Micro & 142 & 67.6 \\
\hline Small scale & 56 & 26.7 \\
\hline Medium scale & 12 & 5.7 \\
\hline Total & 210 & 100 \\
\hline \multicolumn{3}{|l|}{ Customer type } \\
\hline Male only & 24 & 11.4 \\
\hline Female only & 26 & 12.4 \\
\hline Both & 160 & 76.2 \\
\hline Total & 210 & 100 \\
\hline \multicolumn{3}{|l|}{ Location of the company } \\
\hline Accra & 48 & 22.9 \\
\hline Kumasi & 114 & 54.3 \\
\hline Sunyani & 48 & 22.9 \\
\hline Total & 210 & 100 \\
\hline
\end{tabular}

Most $(54.3 \%)$ of the respondents were drawn from Kumasi, $22.9 \%$ from Sunyani and the rest from Accra. $86.7 \%$ of them were between the ages of 21 and 40 years with none of them exceeding 60 years. Over $70 \%$ have had their highest educational qualification ranging from HND to PhD with the rest being Elementary/ Junior High School (JHS), Intermediate, Senior High and Advance certificate holders. Those who have worked in the garment industry between 1 and 15 years constituted $81.8 \%$ whereas those with less than 1 year experience amounted to $10.5 \%$ with the least (7.7\%) having the longest working experience being 16 years and above. The results thus suggest that the respondents have remarkable experience that could be counted on in a study like this. More than $97 \%$ of the respondents belong to the local industry and close to $95 \%$ of them fall within either the micro enterprise category or small scale whilst the rest belong to the medium scale confirming the Ghana Skills Development Initiative (2013-2017) report which indicates that most enterprises in Ghana are small-scale, some are medium sized, and very few can be categorized as large. 
Over $76 \%$ sew for both sexes (male and female) whilst the rest were for either male or female only (Table 1). Over $71 \%$ of the respondents were either owners or managers of their companies, $26.7 \%$ workers and $1.9 \%$ apprentices who had been mandated to participate in the study by their owners (Figure 1). A chunk of them (71.4\%) used both local and foreign fabrics whereas the remaining used either only foreign or only local fabrics (Figure 2).

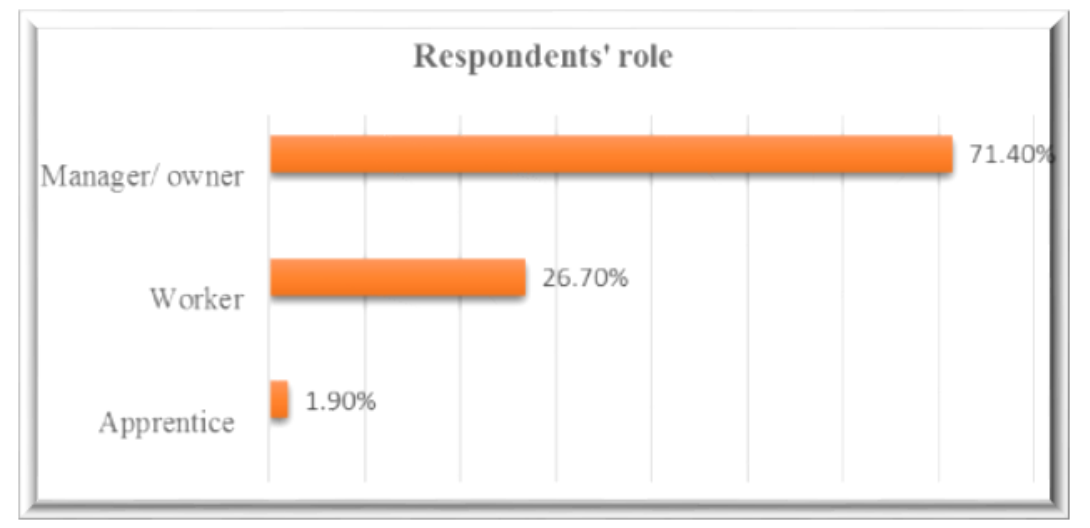

Figure 1: Respondents' role in company

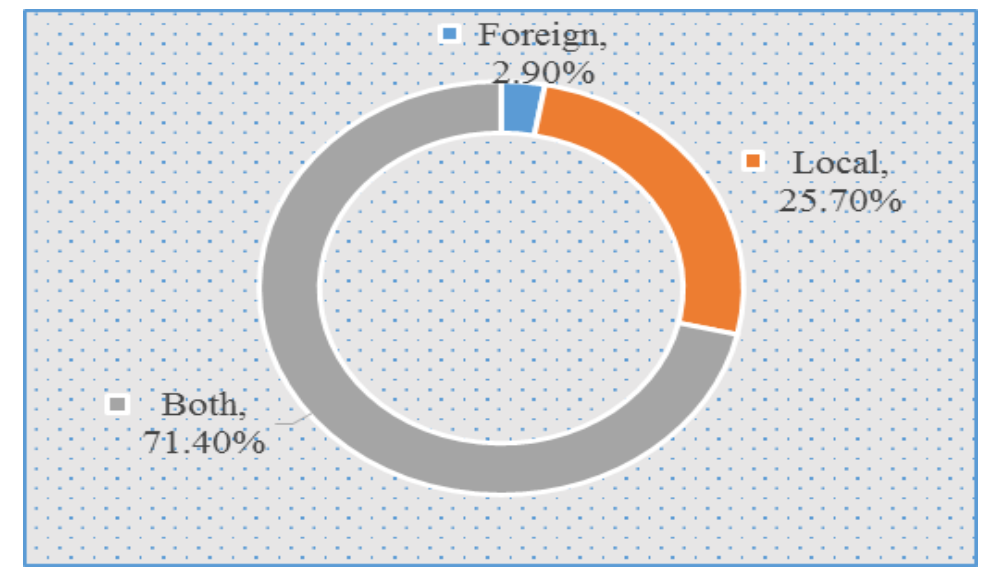

Figure 2: Type of fabric used by respondents' companies

\subsection{Costing Strategies in the Study Areas}

\subsection{1: Procedure for Determining the Production Cost of Garments}

It was crucial to ascertain the various strategies used when costing garments in the fashion industry. In doing so, the steps to follow in costing and factors considered were studied and the results are in Tables 2 and 3 . The result in Table 2 depicts that more fashion industries $(2.58 \pm 0.583)$ to either "a great" or "moderate extent" do actual costing followed by detailed costing $(2.07 \pm 0.736)$. The results further show that cost estimates $(1.99 \pm 0.712)$ and preliminary costing $(1.86 \pm 0.698)$ are not popular among the fashion industries in the study areas. This means that more designers devote their time in preparing detailed costing and actual costing as against the others probably due to the nature of the fashion industries in Ghana. Literature presents that preliminary costing, cost estimating, detailed costing, and actual costs are the four different stages of garment costing and the number of steps to be followed by a specific company is influenced by its size and the process structure (Myers-McDevitt 2011, 13-14) hence the result obtained.

Table 2 : Respondents' Procedure for Determining the Production Cost of Garment

\begin{tabular}{lcccccc}
\hline Procedure & N & Min & Max & Mean & St. D & Remarks \\
\hline Preliminary costing & 210 & 1 & 3 & 1.86 & 0.698 & Not popular \\
Cost estimating & 210 & 1 & 3 & 1.99 & 0.712 & Not popular \\
Detailed costing & 210 & 1 & 3 & 2.07 & 0.736 & Popular \\
Actual costing & 210 & 1 & 3 & 2.58 & 0.583 & Popular \\
\hline
\end{tabular}

\subsubsection{Garments Costing Factors}

The cost of garment covers items such as fabric, trims, cut, make and trim charges, value added services (such as printing, embroidery, washing, applique), testing of the garment quality, transportation and logistics cost and profit of the manufacturing organization (Kothari, 2013). 
From Table 3, the first five factors mostly considered when costing garments are profit, fabric cost, labor cost, trim cost and overheads whilst the five least important ones are the margin, rejection and wastage, testing and inspection charges, commission on foreign exchange and commission on buying a house. The result may be due to the nature of the fashion industries in Ghana.

Table 3: Factors Important to Garment Costing in Ghana

\begin{tabular}{lcccccc}
\hline Factor & Number & Min & Max & Mean & St. D & Ranking \\
\hline Profit & 210 & 1 & 5 & 4.16 & 1.108 & 1 \\
Fabric cost & 210 & 1 & 5 & 3.90 & 1.348 & 2 \\
Labor cost & 210 & 1 & 5 & 3.81 & 1.276 & 3 \\
Trim cost & 210 & 1 & 5 & 3.62 & 1.278 & 4 \\
Overheads charges & 210 & 1 & 5 & 3.44 & 1.431 & 5 \\
Sales Commission & 210 & 1 & 5 & 3.34 & 1.368 & 6 \\
Transport charges & 210 & 1 & 5 & 3.00 & 1.363 & 7 \\
Cut and make trim charges & 210 & 1 & 5 & 2.96 & 1.424 & 8 \\
Margin & 210 & 1 & 5 & 2.85 & 1.392 & 9 \\
Rejection and wastage & 210 & 1 & 5 & 2.81 & 1.497 & 10 \\
Test and inspection charges & 210 & 1 & 5 & 2.60 & 1.415 & 11 \\
Commission on foreign exchange & 210 & 1 & 5 & 2.50 & 1.445 & 12 \\
Commission buying a house & 210 & 1 & 5 & 2.30 & 1.3364 & 13 \\
\hline
\end{tabular}

\subsubsection{Factors Influencing Garment Pricing in Ghana}

In determining the garment pricing strategies in the fashion industry, it was essential to verify the various influencing factors, the pricing approaches and the tips for successful pricing. Table 4, 5 and 6 address that. Table 4 displays the results of the factors essential to garment pricing in Ghana. This result affirms that odds and cents pricing (Carmin et al., 1990; Liang \& Kanetkar, 2006; Naipaul \& Parsa, 2001), quality of the product, costs, characteristics, location, and competition (Carmin et al., 1990), status (LaFontaine, 1995; Graddy, 1999; Ater et al., 2010; Kalnins, 2003) and demographics of the area (Graddy, 1997; Stewart \& Davis, 2005) including the racial composition of an area have influence on pricing. However, quality of the garments (4.28 \pm 0.953$)$, market competition $(3.70 \pm 1.269)$ and garment production cost $(3.63 \pm 1.325)$ are the top three most important ingredients worthy of consideration when taking pricing decisions in the Ghanaian garment industry. Racial composition of the area $(2.73 \pm 1.492)$ and odd and cent pricing $(2.24 \pm 1.226)$ are the least considered. An interaction with some of the respondents revealed that some occasionally consider the racial inclination of their clients to price their products.

Table 4: Factors Influencing Garment Pricing in Ghana

\begin{tabular}{lcccccc}
\hline Factor & N & Min & Max & Mean & St. D & Ranking \\
\hline Quality of the garments & 210 & 1 & 5 & 4.28 & 0.953 & 1 \\
Market Competition & 210 & 1 & 5 & 3.70 & 1.269 & 2 \\
Garment production cost & 210 & 1 & 5 & 3.63 & 1.325 & 3 \\
Characteristics of the firm & 210 & 1 & 5 & 3.46 & 1.276 & 4 \\
Age of the consumers & 210 & 1 & 5 & 3.30 & 1.356 & 5 \\
Firm /company location & 210 & 1 & 5 & 3.30 & 1.445 & 6 \\
Population of the area & 210 & 1 & 5 & 2.95 & 1.400 & 7 \\
Racial composition of the people in the area & 210 & 1 & 5 & 2.73 & 1.492 & 8 \\
Odd and cents pricing & 210 & 1 & 5 & 2.24 & 1.226 & 9 \\
\hline
\end{tabular}

\subsubsection{Approaches to Garment Pricing in Ghana}

Table 5 confirms that cost-plus pricing ( $\mathrm{Li}, 2014)$, market-based pricing (Phillips 2005, 24), value-based pricing (Phillips 2005, 24-26), good-value pricing (Li, 2014), high and low (Li, 2014), yield management (Ross and Johns, 1997; Boahen, Quansah \& Sarpong, 2013), price skimming (Dolgui \& Proth, 2017), price testing (Dolgui. \& Proth, 2010), discount strategy (Bolton, 1989), competition-based pricing (Liozu \& Hinterhuber, 2012), market segmentation (or price discrimination) strategy (Dolgui \& Proth, 2017), estimation by experts' method (Dolgui \& Proth, 2017) and market analysis (Radulescu, 2012) are the strategies employed for pricing garments. 
Table 5: Approaches to Garment Pricing in Ghana

\begin{tabular}{lcc}
\hline Approach & \% frequency & Ranking \\
\hline Cost plus method & 24.34 & $1^{\text {st }}$ \\
Market analysis & 8.48 & $2^{\text {nd }}$ \\
Discount strategy & 7.60 & $3^{\text {rd }}$ \\
Customer based pricing & 6.74 & $4^{\text {th }}$ \\
Market segmentation (or price discrimination) strategy & 6.30 & $5^{\text {th }}$ \\
Price testing & 5.87 & $6^{\text {th }}$ \\
Customer Survey & 5.65 & $7^{\text {th }}$ \\
Penetration pricing & 5.65 & $7^{\text {th }}$ \\
Yield management & 5.43 & $9^{\text {th }}$ \\
The value based approach or perceived value pricing & 5.22 & $10^{\text {th }}$ \\
Price skimming & 5.00 & $11^{\text {th }}$ \\
Estimation by experts & 5.00 & $12^{\text {th }}$ \\
Competition based pricing & 4.35 & $13^{\text {th }}$ \\
High and low pricing & 4.35 & $13^{\text {th }}$ \\
\hline
\end{tabular}

Among the 14 approaches to pricing, cost plus method (24.34\%), market analysis (8.48\%) discount strategy (7.60\%) and customer based pricing $(6.74 \%)$ seemed to be widely employed in the Ghanaian garment industries more than the others. However cost plus method is the most used method of pricing whereas the least employed methods are the competition based pricing (4.35\%) and the high and low pricing (4.35\%) (Table 5). This result confirms Li (2014) and Tettehfio (2009) whose findings point to cost plus method being the most popular approach in garment pricing. The study also found that some fashion providers fix their prices based on the instructions from their associations whilst others put aside a percentage of the cost to cater for the overheads and profit. There were yet others who set their prices to be at par with their competitors for fear of losing their customers.

\subsubsection{Tips for Pricing Success}

Verifying the tips necessary for pricing success was found to be crucial in the study since these factors might boost profitability. Table 6 depicts that most respondents were of the view that for successful pricing of garments, fashion designers / dress makers should be guided by tips such as: being creative (that is thinking of new ways to sell more to existing customers or attracting new ones); listening to their customers (meaning noting customer comments in a file or journal and periodically reviewing them); doing their homework well (which means keeping good notes of how they arrived at a price so as to make similar assumptions in future); boosting their records (that is a good recordkeeping helps set a price and track its performance); covering the basics (blending pricing methods, that is. product price, competition and customers to ensure the three basics in pricing are in a balance) and being flexible by constantly reviewing both internal and external factors and calculating how a price change would affect the new situation. The outcome confirms the recommendations in the facts sheets presented by Alberta Agriculture Food and Rural Development (1999) which states that to ensure greater pricing success the afore stated tips are appropriate.

Table 6 : Tips necessary for pricing success

\begin{tabular}{lccccc}
\hline \multirow{2}{*}{ Tips } & \multicolumn{5}{c}{ Level of Confirmation } \\
\cline { 2 - 6 } & N & Min & Max & Mean & St. Dev \\
\hline Being creative & 210 & 1 & 5 & 4.12 & 1.107 \\
Listening to your customers & 210 & 1 & 5 & 4.32 & 0.923 \\
Doing your homework well & 210 & 1 & 5 & 4.35 & 0.968 \\
Boosting your records & 210 & 1 & 5 & 4.52 & 0.831 \\
Cover the basics & 210 & 1 & 5 & 4.52 & 0.831 \\
Being flexible & 210 & 1 & 5 & 4.53 & 0.819 \\
\hline
\end{tabular}

It is believed that if Ghanaian fashion industries pay heed to these afore-stated tips, there will be successful pricing and a boost in profit margins, otherwise the pricing problems will persist.

\subsubsection{Satisfaction Level of the Fashion Enterprises in Ghana}

The extent to which fashion industries were satisfied with their profits margin was important to the study. This will give clear picture as to how the fashion industries are faring and for which the needed assistance could be given. The result in Table 7 reveals a higher percentage of satisfaction levels among the enterprises in the study areas and the Kruskal Wallis test $\left(\chi^{2}=7.480, \mathrm{df}=2, \mathrm{p}>0.01\right)$ suggest no significant difference in satisfaction and thus, support the null 
hypothesis. Over $70 \%$ of the respondents were either "satisfied" or "very satisfied" with their profit margins whereas close to $25 \%$ were of the view that they were "somehow satisfied" with a few being "unsatisfied".

The over $27 \%$ of respondents who were either "unsatisfied" or "somehow satisfied" with the profit they accrue from their products is an indication of a remarkable challenge in the industry that needs to be addressed. Challenges that are associated with the basic principles of costing and pricing are rife in the industries/enterprises especially the small and the micro enterprises. Additional data gathered from the field through the unstructured interview revealed that a good number of the enterprises base their pricing strategies on intuition and experience. This result thus corroborates with Simon, (1992) that many companies use intuition and the manager's market experience to determine their prices.

Table 7: Satisfaction Level of the Fashion Enterprises in Ghana. $\left(\chi^{2}=7.480, \mathrm{df}=2, \mathrm{p}>0.01\right)$

\begin{tabular}{lcccccc}
\hline & \multicolumn{5}{c}{ \% Satisfaction level } \\
Type of Enterprise & 1 & 2 & 3 & 4 & 5 & Total \\
\hline Micro & 0 & 1.9 & 19 & 57.1 & 9.5 & 67.6 \\
Small scale & 1 & 0 & 5.7 & 13.3 & 6.7 & 26.7 \\
Medium scale & 0 & 0 & 0 & 3.8 & 1.9 & 5.7 \\
Total & $\mathbf{1 . 0}$ & $\mathbf{1 . 9}$ & $\mathbf{2 4 . 8}$ & $\mathbf{5 4 . 3}$ & $\mathbf{1 8 . 1}$ & $\mathbf{1 0 0}$ \\
\hline Legend: Very' unsatisfied (1): Unsatisfied (2): Somehow satisfied (3): Satisfied (4): Very satisfied (5)
\end{tabular}

\section{Conclusion}

The core aim of the study was to verify the various strategies for costing and pricing of garments in the Fashion Industry of Ghana. In achieving that mixed method approach was used to collect data from 210 respondents in the Fashion Industry made up of owners, workers and a few apprentices. Generally, companies performed detailed and actual costing by mostly considering factors such as the expected profit, fabric cost, trim cost, and overheads charges among others. Factors like the quality of the fabric, firm characteristics, market competition, production cost, age of the client and business location played important role in fixing garment prices. Among the top approaches to garment pricing for instance, cost plus method, market analysis, discount strategy, customer based pricing, market segmentation and others, cost plus method was found to be most popular in the fashion industry. Enterprises were largely satisfied with their profit margin with no significant difference between their ratings. Challenges associated with costing and pricing were inherent in the study and resultantly, some of the enterprises specifically the micro and small scale ones used intuition and experience to fix their prices without considering overheads. Though on the whole, the satisfaction level was high, it is important that we do not gloss over the effect of the over $27 \%$ of the respondents who were either "unsatisfied" or "somewhat satisfied" with their profits margin. Obviously these respondents might be battling with a lot of challenges that affect their businesses and therefore need to be holistically addressed. It is believed that when the fashion providers are educated on the basic cost estimates and pricing principles, it will go a long way in curbing the problem if not totally eliminating it. The study has so far hinted on a few challenges plaguing the Fashion Industry and it is therefore apt to carry out extensive research into the various costing and pricing challenges inherent in the industry for which profits margins are affected.

\section{Recommendations}

- Associations in the fashion industries such as the tailors and dressmakers' association should be educated on the need to do effective pricing of their products.

- In order to avoid waste and ensure judicious use of resources, trainees must be taught how to determine the right quantity of fabric and thread required for a particular garment style.

- Teaching of costing and pricing principles should be strengthened in the training institutions so as to get trainees better equipped for the world of work.

\section{Limitation}

The study applied non probability sampling to choose companies and to this effect, findings cannot be generalized to represent what pertains nation-wide. It is only for the study areas.

\section{Acknowledgement:}

We are grateful to all those personalities who in diverse ways contributed immensely to the success of the study, especially to Mr Kweku Bedu Simpson- Department of Architectural Drafting- Accra Technical Training CentreAccra. 


\section{References}

Agriculture Business Strategies (1999) Methods to Price Your Product. Alberta Agriculture Food and Rural Development. Retrieved from https://www.agmrc.org/media/cms/8452_B4C31E4164D0A.pdf

Amankwah, A.M. Howard E. K. \& Sarpong G.D. (2012). Foreign fashion influence on the Ghanaian youth and its impact on the local fashion industry. International Journal on Innovative Research and Development. Vol. 1 Issue $11 \mathrm{pp}$ 562-575.

Amankwah, A.M., Badoe W. \& Chichi, C. A. (2014) Ripple Effect of a Vibrant Fashion Industry on Graduate Unemployment. Research on Humanities and Social Sciences Vol.4, No.28, 2014. https://www.researchgate.net/publication/275950423_Ripple_Effect_of_a_Vibrant_Fashion_Industry_on_Gra duate_Unemployment (assessed 14/11/18)

Ampofo, V. O. (2011). Ghana's textile/garment industry. Ghana: Industrial development and Investment Division, Ministry of Trade and Industry.

Ater, I. and Rigbi. O. (2010). Price Control in Franchised Chains: The Case of McDonald's Dollar Menu. SIEPR Discussion Paper. No. 0622.

Aryeety, E., Kayanula D, \& Quartey P. (1994). Supply and Demand for Finance of Small Enterprises in Ghana. World Bank Discussion Paper. (No. 251).

Barth J. E, (2002). Yield management: opportunities for private club managers. International Journal of Contemporary Hospitality Management, 14:136-141

Bemmaor, A.C., Mouchoux, D., (1991). Measuring the short-term effect of in-store promotion and retail advertising on brand sales: A factorial experiment. Journal of Marketing Research 28: 202 - 214. http://siteresources.worldbank.org/INTPRS1/Resources/383606-

1201883571938/Cost_Definitions_and_Methods.pdf

Blattberg, R.C. \& Neslin, S.A., (1990). Sales Promotion: Concepts, Methods and Strategies. Prentice-Hall, Englewood Cliffs, NJ.

Boahen, O. Quansah E.K \& Sarpong O.K (2013). Assessing the Benefits of Yield Management in the Hospitality Industry in Kumasi Metropolis of Ghana. International Journal of Business and Social Research (IJBSR), Volume -3, No.-9, page 17-25.

Bolton, R.N., (1989). The relationship between market characteristics and promotional price elasticities. Marketing Science 8: $153-169$.

California Fashion Association, "The Los Angeles Area Fashion Industry Profile" (November 2011)

Carmin, J. \& Norkus G. (1990). Pricing Strategies for Menus: Magic or Myth. Cornell Hotel and Restaurant Administration Quarterly 31(3): 44-50.

Choudhary A. S. (2015). Cost Analysis in Garment Industry. International Journal of Recent Advances in Multidisciplinary Research Vol. xx Issue xx ppxx www.researchgate.net/publication/282604549

Cross R.G., (1997). Launching the Revenue Rocket: How Revenue Management Can Work for Your Business. The Cornell Hotel and Restaurant Administration Quarterly, 38(2): 32-43.

Dolgui A. \& Proth J-M (2017) Pricing strategies and models. Article in Annual Reviews in Control • April 2010 DOI: 10.1016/j.arcontrol.2010.02.005 - Source: DBLP. Retrieved from https://www.researchgate.net/publication/220531085

Dramedo B.E. (2009) Clothing and Fashion in Ghanaian Culture: A case study among the Akans. Retrieved 15/11/18 from Ir.knust.edu.gh>bitstream>clothing

Easey, M. (2002). Fashion Marketing. (Second Edition), Blackwell, UK.

Esse T, (2003). Securing the Value of Customer Value Management, Journal of Revenue and Pricing Management. Volume 2, Issue 2, pp 166-171

Essel O.Q. and Ammissah E.R.K., (2015). Smock Fashion Culture in Ghana's Dress Identity-Making. Retrieved 22/12/18 from http://www.iiste.org>article > view

Frankael, J R \& Wallen, N. E. (2003). How to Design and Evaluate Research in Education, (5th Ed.). New York- -169 McGraw-Hill companies.

Gandhi, M.K. \& Poonkuzhali S. (2015) Effective Cost Analysis Model for Apparel Industry International Journal of Applied Engineering Research ISSN 0973-4562 Volume 10, Number 8 (2015) pp. 20263-20276

Ghanaian Enterprises Development Act - 1975 (NRCD 330).

Ghana Skills Development Initiative, 2013-2017. Retrieved 5/8/18 from http://www.ghanaskills.org/node/7.

Global Fashion Industry Statistics -International Apparel. Retrieved 6/17/2018 from https://fashionunited.com/

Goworek, H. (2007). Fashion Buying. 2nd ed. Oxford: Blackwell Publishing. 
Graddy, K. (1997). Do Fast-Food Chains Price Discriminate on the Race and Income Characteristics of an Area? Journal of Economic and Business Statistics 15: 391-401.

Graddy, K., \& Robertson D. (1999). Fairness of Pricing Decisions. Business Ethics Quarterly 9(2): 225-243.

Heil, O. P., \& Helsen, K. (2001). Toward an understanding of price wars: Their nature and how they erupt. International Journal of Research in Marketing, 18(1), 83-98

Hinterhuber, A. (2008). Customer value-based pricing strategies: Why companies resist. Journal of Business Strategy, 29(4), 41-50.

Hinton, P.R. (2004). Statistics explained. 2nd edition. Routledge, London and New York. Retrieved 4/4/16 from http://library.aceondo.net/ebooks/Mathematics/Statistics_Explained-

A_Guide_for_Social_Science_Students.pdf

Isaac, S. \& Michael, W.B. (1995). Handbook in Research and Evaluation. San Diego, CA, Edits Publishers.

Jekanowski, M. D. (1998). An Econometric Analysis of the Demand for Fast Food across Metropolitan Areas with an Emphasis on the Role of Availability. PhD Dissertation, Purdue University, West Lafayette, IN.

Jeffrey, M. \& Evans, N. (2011). Costing for the Fashion Industry. 1st ed. Oxford OX4 1AW, UK: Berg, Bloomsbury Publishing Plc.

Jennings, H. (2011) New African Fashion. Munich: Prestel.

Juran, J. M., \& De Feo, J. (2010). Juran's quality handbook: The complete guide to performance excellence (6th Ed.). New York: McGraw-Hill.

Kalnins, A. (2003). Hamburger Prices and Spatial Econometrics. Journal of Economics and Management Strategy 12(4): 591-616.

Kayanula D. \& Quartey, P. (2000). The Policy Environment for Promoting Small and Medium Sized Enterprise in Ghana and Malawi. Finance and Development Research Programme Working Paper. Series No.15.

Keiser, S. J., \& Garner. M.B. (2008). Beyond Design - The Synergy of Apparel Product Development. 2nd Ed. New York: Fairchild Publications, Inc.

Kimes, S. E. (1989). The basics of yield management [Electronic version]. Cornell Hotel and Restaurant Administration Quarterly, 30(3), 14-19. Retrieved [insert date], from Cornell University, School of Hospitality Administration site: http://scholarship.sha.cornell.edu/articles/456/

Kothari, V. R. (2013) Fashion merchandising: garment costing. Retrieved 6/17/2018 from

LaFontaine, F. (1995). Pricing Decisions in Franchised Chains: A Look at the Restaurant and Fast-Food Industry. NBER Working Paper 5247.

Lavrakas, P. (2008) Cross-Sectional Survey Design In: Encyclopedia of Survey Research Methods http://dx.doi.org/10.4135/9781412963947.n120

Lee-Ross, D. \& Johns, N. (1997). Yield management in hospitality SMEs. International Journal of Contemporary Hospitality Management, 9(2), 66-69

Li C. (2014) Retail Pricing Strategies and Tactics. Pearson Education, Dublin. Retrieved 1/12/18 from http://mafe.wzw.tum.de/fileadmin/user_upload/Lesson_3.2_Retail_Pricing_UCD.pdf

Liang, J., \& Kanetkar V. (2006). Price Endings: Magic and Math. Journal of Product and Brand Management 15(6): 377-385.

Liozu, S.M. \& Hinterhuber A. (2012) Industrial product pricing: A value-based approach. Journal of Business Strategy, 33 (4) (2012), pp. 28-39

Madichie, N.O. (2009). Breaking the Glass Ceiling in Nigeria: A review of Women's Entrepreneurship. Journal of Africa Business. Vol. 10, 2009. Retrieved 12/10/18 https://www.tandfonline.com/doi/abs/10.1080/15228910802701361.

Myers-McDevitt, P. J. (2011). Apparel Production Management and the Technical Package. 1st Ed. New York: Fairchild Books.

Nagle, T., \& Holden, R. K. (2003). Estratégias e táticas de pre scos: um guia para as decisões lucrativas. São Paulo: Prentice Hall.

Naipaul, S., \& Parsa, H.G. (2001). Menu Price Endings that Communicate Value and Quality. Cornell Hotel and Restaurant Administration Quarterly 42(1): 26-37.

NBSSI (1990), "Supporting Micro \& Small Scale Enterprises". A handbook on Enterprise Development Part 1. NBSSI, Print Solutions, Accra.

Nkube, A. (2018) Fashion Design Industry: Capturing Value through Intellectual Property. http://www.chronicle.co.zw.fashion-de

Osei, B., Baah-Nuakoh, A., Tutu, K.A. \& Sowa, N.K. (1993) Impact of Structural Adjustment on Small-Scale Enterprises in Ghana. In: Helmsing, A.H.J and Kolstee, T.H., Eds., Structural, Financial Policy and Assistance Programmes in Africa, IT Publications. 
Osei Kwadwo N., (2014). The business of street fashion in Accra. Retrieved 26/6/18 from https://accradotalttours.wordpress.com/2014/.../the-business-of-street-fashion-in-accra

Phillips, R. (2005). Pricing and Revenue Optimization. Palo Alto, CA, USA: Stanford Business Books. http://site.ebrary.com/lib/metropolia/docDetail.action?docID=10483644.

Porter, M. (1986). Estratégia competitiva: técnicas para análise de indústrias e da concorrência (17th Ed.). Rio de Janeiro: Campus.

Quartey P. (2006). The Textiles and Clothing Industry in Ghana in: Herbert Jauch / Rudolf Traub-Merz (Eds.) The Future of the Textile and Clothing Industry in Sub-Saharan Africa Bonn: Friedrich-Ebert-Stiftung, 2006

Radulescu. V. (2012). The Role of Market Analysis in Developing Efficient Marketing Audit. from:https://www.researchgate.net/publication/268392968_The_Role_of_Market_Analysis_in_Developing_Ef ficient_Marketing_Audit [accessed Dec 08 2018]

Sarpong, G. D. Howard E.K \& Osei-Ntiri, K. (2011). Globalisation of fashion industry and its effect on Ghanaian independent designers. Journal of Science and Technology, Vol. 31, No. 3 (2011), pp 97 - 106.

Simon, H., Bilstein, F. R., \& Luby, Frank. (2008). Gerenciar para o lucro, não para a participa são de mercado. Porto Alegre: Bookman.

Simon, H. (1992). Pricing opportunities and how to exploit them. Sloan Management Review, 33(2), 55

Tashakkori, A. \& Teddlie, C. (2003). Handbook of Mixed Methods in Social and Behavioural Research. Thousand Oaks: Sage.

Tettehfio, L. A. (2009) The Role of the Indigenous Ghanaian Textile Industry In Relation To the President's Special Initiative (Psi) On Textiles and Garments. Unpublished Doctoral thesis.

ir.knust.edu.gh/xmlui/handle/123456789/288?show=full

The Economic Impact of the Fashion Industry- Joint Economic Committee (2015). Retrieved 12/11/18 from https://www.jec.senate.gov>reports

Vogt, W. P. (1999) Dictionary of Statistics and Methodology: A Nontechnical Guide for the Social Sciences, London: Sage.

Zeithaml, A. (1988). Consumer perceptions of price, quality, and value: A means end model and synthesis of evidence. Journal of Marketing, 52(3), 2-22. 